\title{
“QUE LETRA BONITA! CONTINUE ASSIM!": REGISTROS DE PROFESSORAS ALFABETIZADORAS EM CADERNOS DE ALUNOS SOBRE O ENSINO E O USO DOS TIPOS DE LETRAS
}

\author{
Alessandra Amaral da Silveira \\ Universidade Federal do Rio Grande \\ ale82amaral@yahoo.com.br \\ Caroline Braga Michel \\ Universidade Federal do Rio Grande \\ carolibrga@yahoo.com.br
}

\section{RESUMO}

Este artigo analisa os registros de professoras em cadernos de alfabetização que apresentam orientações, indicações e sugestões no que tange ao ensino e ao uso dos diferentes tipos de letras. A análise realizada em 200 cadernos, de 2000 a 2015, salvaguardados em um Centro de Memória brasileiro, permitiu identificar diferentes registros que foram organizados em duas categorias: "Elogios e Incentivos sobre as letras" e "Solicitações e Recomendações sobre as letras". $\mathrm{Na}$ primeira, observaram-se registros que demonstram o contentamento das professoras com os avanços e progressos dos alunos quanto ao traçado das letras. Na segunda, identificou-se um conjunto de atividades e recursos utilizados para o treino e aperfeiçoamento das letras, por ainda não apresentarem um 'traçado ideal'.

Palavras-chave: Cadernos de alunos. Alfabetização. Tipos de letras.

\section{"!QUÉ LINDA LETRA! CONTINUE ASÍ!": REGISTROS DE MAESTRAS ALFABETIZADORAS EN CUADERNOS CUADERNO DE ESTUDIANTE SOBRE LA ENSEÑANZA Y EL USO DE LOS TIPOS DE LETRAS.}

\section{RESUMEN}

Este artículo analiza los registros de las maestras en cuadernos de alfabetización en los cuales se encuentran orientaciones, indicaciones, y sugerencias en relación a la enseñanza y al uso de los diferentes tipos de letras. El análisis fue realizado en 200 cuadernos de los años 2000 a 2015 , preservados en el Centro de Memória Brasileiro [cb1]. El mismo permitió identificar diferentes registros que fueron organizados en dos categorías en relación a la letra: "Elogios e incentivos" y "Recomendaciones". En la primera se demuestra el nivel de conformidad de las maestras con el avance de los alumnos en relación al trazado; en la segunda se identifican un conjunto de actividades y recursos utilizados para el entrenamiento y perfeccionamiento grafo-motriz de los alumnos que presentan dificultades.

Palabras-clave: Cuadernos estudiante. Alfabetización. Tipos de letra. 


\title{
$(\mathrm{cc}) \mathbf{E Y}$
}

\section{"WHAT A BEAUTIFUL LETTER! KEEP IT UP!": RECORDS OF LITERACY TEACHERS IN STUDENT NOTEBOOKS ON THE TEACHING AND USE OF LETTER TYPES}

\begin{abstract}
This paper examines the registers of literacy teachers in school notebooks containing orientations, indications, and suggestions on the teaching and usage of different letter types. The analysis was based on 200 notebooks, from 200 to 2015, archived in a Brazilian Memory Center [cb1]. Different registers were identified and separated into two categories: "Compliments and incentives on the letters" and "Requests and recommendations on the letters". In the first one, registers were observed to demonstrate the teachers' satisfaction with the progress of students on the shapes of their letters. In the second one, a set of activities and tools were identified for training to upgrade the letters which did not show an "ideal shape".
\end{abstract}

Keywords: Student notebooks. Literacy. Letter types.

\section{“QUELLE BELLE ECRITURE! CONTINUEZ COMME ÇA!”: REGISTRES DES PROFESSEURS D'ALPHABETISATION DANS LES CAHIER ETUDIANT SUR L'ENSEIGNEMENT ET L'UTILISATION DES LETTRES}

\begin{abstract}
RÉSUMÉ
Cet article analyse les registrements des enseignants dans des cahiers d'alphabétisation qui présentent des lignes directrices, des indications et des suggestions concernant l'enseignement et l'utilisation de différents types de lettres. L'analyse réalisée sur 200 cahiers, de 2000 à 2015, conservés dans un centre de mémoire brésilien, a permis d'identifier différents documents qui ont été organisés en deux catégories: «Compliments et incitations sur les lettres» et «Demandes et recommandations sur les lettres». Dans le premier, des enregistrements ont été observés qui démontrent la satisfaction des enseignants face aux progrès des élèves et aux progrès concernant la mise en page des lettres. Dans le second, un ensemble d'activités et de ressources utilisées pour la formation et la mise au point des lettres a été identifié, car ils n'ont pas encore de trace idéale.
\end{abstract}

Mots-clés: Cahier étudiant. Alphabétisation. Lettres.

\section{INTRODUÇÃO}

Os cadernos de alunos são artefatos da cultura material escolar que apresentam diferentes concepções e ações escolares e pedagógicas. De acordo com Gvirtz (1996), Chartier (2007) e Viñao (2008) o caderno não é mero suporte físico. Pelo contrário, ele pode ser considerado um dispositivo pedagógico, uma vez que materializa muitas das propostas pedagógicas desenvolvidas na sala de 


\section{$(c)$ EY}

aula, os procedimentos adotados pelas professoras no desenvolvimento de determinadas atividades e, até mesmo, por vezes, o funcionamento da escola.

Os registros materializados nos cadernos escolares apresentam indícios que possibilitam uma aproximação com as culturas escolares vivenciadas em diferentes tempos e espaços bem como, contribuem para entender a produção, a modificação ou a permanência de determinadas práticas didático-pedagógicas, de políticas ou de pedagogias vigentes em diferentes épocas. Propicia, ainda, confrontar o ensino idealizado pelas concepções pedagógicas e políticas com o aprendizado colocado em funcionamento nas escolas, uma vez que permitem pensar sobre o “vivido" na sala de aula (VIÑAO, 2008; HÉBRARD, 2001).

Desse modo, o caderno escolar vem sendo considerado fonte e/ou objeto em distintas pesquisas de maneira privilegiada, especialmente, por dois motivos: primeiro, por ser caracterizado como um suporte quase sempre de uso diário; segundo, por ser um espaço de interações de diferentes sujeitos (alunos, professores, responsáveis e/ou familiares, direção, entre outros). Compreende-se, portanto, que os cadernos escolares são tanto produto quanto "produtor da cultura escolar"; eles são "geradores de discursos específicos e de efeitos específicos" (GVIRTZ; LARRONDA, 2008, p. 45), porque eles colocam em funcionamento diferentes saberes que estão vinculados ao lugar da sua produção. Em síntese, pode se dizer que se entende, assim como Viñao (2008), que o caderno escolar tem se tornado um documento significativo para pensar a história da educação, pois:

[...] os cadernos não são apenas um produto de atividades realizadas na sala de aula (afinal o livro texto é um produto exterior que se introduz em sala de aula) e da cultura escolar, mas também uma fonte que fornece informação - por meio, sobretudo, de redações e composições escritas - da realidade material da escola e do que se faz nela. (VIÑAO, 2008, p. 16).

Na esteira dessa compreensão, nas últimas décadas, têm sido desenvolvidas inúmeras pesquisas, no Brasil e no exterior, que apresentam os cadernos como fonte e/ou objetos. Em âmbito internacional, cabe destacar na França, os trabalhos de Chartier (2002, 2007, 2007a) e Hébrard (2001, 2007); na Espanha, os de Viñao (2008), Andrés e Zamora (2008) e Gómez (2010, 2012); na Argentina, os de Gvirtz (1996, 1997), Gvirtz e Larrondo (2008). Em linhas gerais, enfatiza-se que, a partir dos cadernos escolares, as pesquisas desses autores e autoras têm privilegiado temáticas referentes ao currículo, aos tempos escolares, as rotinas, as influências pedagógicas e políticas, as práticas de ensino da leitura e da escrita, entre outras. 
No Brasil, salientam-se, especialmente, os trabalhos de Mignot (2005, 2008a, 2008b), a qual tem organizado livros sobre a temática contemplando investigações nacionais e internacionais. Além da referida autora, cabe destacar as pesquisas de Peres (2010, 2012), Peres, Dietrich e Barum (2011), Santos (2002), Lopes (2006), Jacques (2011) e Neubert (2013); as quais versam, dentre outros aspectos, sobre as marcas manuscritas de professoras alfabetizadoras em cadernos de alunos, as permanências e mudanças na forma de correção das atividades escolares, as memórias e discursos presentes nas marcas de correções em cadernos escolares, a naturalidade e permanência dos cadernos no espaço e tempo da escola e os sentidos atribuídos pelas crianças aos seus cadernos. É importante mencionar ainda, que, conforme consta na Biblioteca digital brasileira de teses e dissertações (BDTD), desde os anos 2000 o número de produções que tem o caderno escolar como fonte e/ou objeto vem aumentando significativamente no país ${ }^{1}$.

Observa-se, pelos vieses de alguns dos trabalhos que vêm sendo realizados, que o caderno é um importante testemunho de escrita (HÉBRARD, 2001) e que apresenta indícios que possibilitam investigar diferentes facetas da cultura escolar. Em contato com os cadernos escolares, é possível perceber, por exemplo, as rotinas do trabalho docente, o currículo, o objeto de conhecimento, as avaliações, os métodos, as relações estabelecidas entre professoras, alunos e famílias, assim como, a materialidade, seus usos e as subjetividades produzidas a partir da interação do sujeito com o caderno escolar. Contudo, observa-se, que a proposta apresentada neste artigo, articulada às temáticas da cultura material, da alfabetização e do ensino das tipologias das letras ${ }^{2}$, têm sido pouca explorada. Diante disso, este artigo tem como intuito analisar os registros de professoras em cadernos de alunos em início do processo de escolarização, que apresentam, especificamente, indicações, sugestões e orientações sobre o ensino e o uso de diferentes tipos de letras ${ }^{3}$, a saber: cursiva, imprensa minúscula e imprensa maiúscula ${ }^{4}$. É importante frisar que por letra cursiva entende-se "[...] as letras de uma palavra que são tôdas ligadas umas às outras."

\footnotetext{
${ }^{1}$ Até o começo de 2020 foram produzidos aproximadamente 20 teses e dissertações no país que tiveram os cadernos escolares como fonte e/ou objeto de pesquisa vinculada a diferentes áreas como, por exemplo, psicologia, direito, linguística. Contudo, a maior parte foi realizada na área da educação, com ênfase na História da Educação.

${ }^{2}$ Nos últimos anos as autoras vêm se dedicando a diferentes pesquisas que contemplam essas temáticas. Dentre elas, faz-se referência à pesquisa que teve como objetivo fazer uma tipologia das letras usadas nas classes de alfabetização de diferentes escolas gaúchas ao longo de 78 anos (1937 a 2015). Para isso, foram consultados e analisados um total de 489 cadernos de alunos de diferentes escolas do Rio Grande do Sul, Brasil.

${ }^{3}$ Uma versão inicial desta temática foi apresentada pelas autoras no $25^{\circ}$ Encontro da Associação Sul-Rio-Grandense de pesquisadores em História da Educação (ASPHE), no ano de 2019.

${ }^{4}$ Essas são as denominações mais usuais nos cadernos de alunos investigados e, também, em documentos oficiais brasileiros nas últimas décadas.
} 


\section{$(c)$ EY}

(FONTOURA, 1963, p. 119); por letra imprensa minúscula, "aquela em que as letras são separadas umas das outras, tal como acontece neste livro, e em todos os impressos, revistas ou jornais [...] data do século XVI com o surgimento da imprensa” (FONTOURA, 1963, p. 120) e, por letra imprensa maiúscula também caracterizada pela separação entre as letras, com formas gráficas e traçados de linhas mais retas em caixa alta (CAGLIARI, 2009).

Trata-se, portanto, de uma análise que foi realizada em cadernos de alunos que se encontram salvaguardados no Centro de Memória brasileiro, situado estado no Rio Grande do Sul, a saber, o Hisales ${ }^{5}$. O mesmo conta com seis acervos, sendo um deles o "Caderno de alunos (ciclo de alfabetização e outras séries)", que é composto por cadernos da Educação Infantil, do ciclo de alfabetização ${ }^{6}\left(1^{\mathrm{a}}\right.$ série $/ 1^{\circ}$ ano, $2^{\mathrm{a}}$ série $/ 2^{\circ}$ ano, $3^{\circ}$ ano), do $4^{\circ}$ e $5^{\circ}$ ano do Ensino Fundamental, dos anos finais do Ensino Fundamental, do Ensino Médio, do Ensino Superior e, ainda, da EJA (Educação de Jovens e Adultos). Até fevereiro de 2020 integravam este acervo 2.116 cadernos de alunos de diferentes localidades do estado do Rio Grande, de outros estados brasileiros e, ainda, de outros países ${ }^{7}$. Contudo, ressalta-se que para a presente análise foram consultados somente os cadernos dos alunos correspondentes ao ciclo de alfabetização ${ }^{8}$, que fossem oriundos do estado do Rio Grande do Sul e pertencentes ao interstício de 2000 a 2015; os quais totalizaram 200 cadernos escolares. A opção por analisar os cadernos de alunos do ciclo de alfabetização ocorreu em virtude de ser neste momento inicial da escolarização que se sistematiza o ensino da leitura e da escrita, sendo, também, portanto, neste momento em que se intensifica o debate sobre o ensino dos tipos de letras (MORAES, 2012; CAGLIARI, 2009).

No conjunto de cadernos de alunos consultados buscou-se, identificar, portanto, os registros escritos por professoras no que tange especificamente ao ensino dos diferentes tipos de letras. Entende-se que esses registros realizados nos cadernos de alunos, pelas professoras, não são neutros, mas sim, produzidos nas mais variadas situações históricas, políticas e culturais. Como

\footnotetext{
${ }^{5}$ Cadastrado como grupo de pesquisa, desde 2006, pela professora Eliane Peres. Localizado na cidade de Pelotas/RS. É um centro de memória e pesquisa, constituído como órgão complementar da Faculdade de Educação (FaE) da Universidade Federal de Pelotas (UFPel). Atualmente sendo coordenado pelas professoras Dra. Eliane Peres, Dra. Vania Grim Thies e Dra. Chris de Azevedo Ramil.

${ }^{6}$ A inclusão do $2^{\circ}$ e do $3^{\circ}$ anos no ciclo de alfabetização foi se alterando conforme a implementação de Políticas Públicas para a Alfabetização no Brasil. Dentre elas, destaca-se no ano de 2006, a aprovação da Lei no 11.274 que implementou o Ensino Fundamental de Nove anos, que, entre outras questões, definiu que o ciclo de alfabetização compreenderia $\mathrm{o} 1^{\circ} \mathrm{e} \mathrm{o} 2^{\circ}$ ano inicial da escolarização. A partir do ano de 2012 foi instaurada a Portaria ${ }^{\circ}-867$, de 4 de julho de 2012, que estabelece o Pacto Nacional pela Alfabetização na Idade Certa e determina que o ciclo de alfabetização passa a ser composto pelo $1^{\circ}$ ano, $2^{\circ}$ ano e $3^{\circ}$ ano.

${ }^{7}$ Como exemplo de outros países cita-se Cuba, Portugal e Cabo Verde.
}

Rev. Iberoam. Patrim. Histórico-Educativo, Campinas (SP), v. 6, p. 1-23, e020015, 2020. 


\section{(c) $) \mathrm{EY}$}

salienta Fischer (2001, p. 199), esses ditos “são uma produção histórica, política; na medida em que as palavras são também construções; na medida em que a linguagem também é constitutiva de práticas”. Nesse sentido, é importante mencionar que os registros das professoras acerca das escritas das crianças com os diferentes tipos de letras nos cadernos elucidam tanto os entendimentos delas acerca das orientações sobre o ensino das tipologias das letras quanto às estratégias e táticas utilizadas neste processo para o 'traçado perfeito' das mesmas nos primeiros anos de escolarização.

Em decorrência disso, os dados apresentados neste artigo foram organizados em duas categorias. A primeira, apresenta os registros das professoras que expressam certa 'satisfação’ em relação aos avanços e progressos dos alunos e alunas sobre o traçado das letras, por isso, apresentam incentivos e elogios sobre as letras. A segunda contempla os registros cuja intencionalidade é qualificar/melhorar o traçado da escrita das crianças e para isso, a professora enfatiza, por meio de seus registros, orientações e estratégias que ela considera ser o ideal para a aprendizagem do traçado das letras. As análises de ambas as categorias, são desenvolvidas na seção seguinte.

\section{AS ESCRITAS DAS PROFESSORAS SOBRE O ENSINO E O USO DOS DIFERENTES TIPOS DE LETRAS: ELOGIOS, INCENTIVOS E ORIENTAÇÕES}

O caderno é um espaço gráfico destinado para o registro de diferentes escrituras (HÉBRARD, 2000). Além de ser considerado um dos suportes mais comuns da instituição escolar, ele é, também, um dos principais lugares da escrita à mão. Desse modo, a partir de investigações realizadas com e neste artefato, é possível ampliar e entender aspectos importantes do cotidiano da escola e das práticas de ensino, assim como rastrear "os traços deixados pelas diversas maneiras de ensinar e aprender através dos tempos” (GÓMEZ, 2012, p. 70). Na esteira desse entendimento, interessa-nos, sobretudo, rastrear aspectos relacionados ao processo de alfabetização e, mais especificamente, do ensino e do uso das tipologias das letras.

Como se sabe, o trabalho desenvolvido nos primeiros anos da escolarização envolve diferentes elementos, tais como o ensino da leitura e da escrita. Neste processo, as professoras desenvolvem variadas estratégias para que as crianças, por exemplo, reconheçam as letras do alfabeto e aprendam seus traçados, assim como sistematizem esses conhecimentos. Comumente essas atividades são registradas nos cadernos e, não raras vezes, quando realizadas em folhinhas, 


\section{(cc) EY}

são fixadas nos mesmos ${ }^{9}$, o que reforça a compreensão dos cadernos enquanto testemunho do trabalho escolar de escrita, assim como um dispositivo de controle (GVIRTZ, 1996; CHARTIER, 2002) na medida em que possibilita que a professora e familiares acompanhem o processo de aprendizagem das crianças, o trabalho proposto e o modo como ele é executado em sala de aula.

Nestes primeiros anos da escolarização, a correção destas atividades, registradas nos cadernos de alunos, pelas professoras, apresenta-se como uma tarefa relevante no cotidiano da sala de aula. Conforme Jacques (2011, p. 62), “essa atividade, em princípio, parece apoiar-se na certeza sobre a importância de se acompanhar o desenvolvimento do aluno e de, a partir da correção, promover possibilidades para que ele adquira determinados conhecimentos e prossiga em sua aprendizagem.".

A análise realizada no conjunto de cadernos consultados, para este artigo, corrobora essa assertiva na medida em que evidencia a recorrência de manifestações de professoras em cadernos de alunos. Do total de 200 cadernos de alunos, notou-se que há, em 95\% deles, alguma forma de registro docente. Ora o uso da letra "V", abreviando a expressão "Visto" como prática de correção e/ou acompanhamento das atividades realizadas, ora bilhetes mais extensos direcionados aos familiares. Tratando-se especificamente das escritas de professoras sobre o ensino e o uso dos diferentes tipos de letras no processo de alfabetização, essa porcentagem é de $17 \%$. Tais registros foram contabilizados em 35 cadernos, que estão assim distribuídos no recorte investigado: 2000 a 2004, dois cadernos; 2005 a 2009, quatro cadernos e de 2010 a 2015, vinte e nove cadernos. Embora haja uma redução na porcentagem ao considerarmos somente as manifestações das professoras referentes ao ensino e ao uso dos diferentes tipos das letras, esse número é representativo, uma vez que evidencia a continuidade na prática dessas profissionais, no decorrer dos anos, em elogiar, corrigir e orientar os traçados das letras nos primeiros anos da escolarização. É interessante frisar, ainda, o aumento significativo de cadernos a partir dos anos 2010 com esse tipo de registro escrito. Apesar de não se ter respostas para este fenômeno, não é improvável que ele esteja vinculado às novas proposições legais brasileiras que vão orientar e recomendar o uso e o ensino de diferentes tipos de letras em cada um dos anos do ciclo de alfabetização.

Sobre essa questão, vale frisar que, no decorrer dos anos 2000, no Brasil, se fortalece a elaboração e implementação de políticas curriculares e de programas de formação docente para a alfabetização, dentre eles, cita-se, como exemplo, o Programa Pró-Letramento - Mobilização pela

\footnotetext{
${ }^{9}$ Para mais informações sobre o trabalho com o recurso didático das folhinhas sugere-se ver Monks (2019).
} 


\section{$(\mathrm{cc}) \mathrm{EY}$}

Qualidade da Educação (2008) ${ }^{10}$ e o Pacto Nacional pela Alfabetização na Idade Certa (PNAIC, 2012) ${ }^{11}$, nos quais são apresentadas orientações para o trabalho pedagógico com os distintos tipos de letras em cada ano do ciclo de alfabetização. Nesse sentido, percebe-se que se passa a ter, por meio dos documentos oficiais, a defesa do uso de uma determinada letra (imprensa maiúscula) nos anos iniciais, quando há a apropriação do sistema de escrita alfabética (MORAES, 2012) e, a orientação de que a ênfase na escrita com a letra cursiva seja somente quando o aluno estiver alfabetizado. Porém, é interessante destacar, que, ao analisar o conjunto de cadernos de alunos selecionados, é perceptível, a partir dos registros docentes, outras lógicas de ensino e o uso de outros tipos de letras no contexto da sala de aula, pois se observa, por meio dos dados, um trabalho e incentivo para com a escrita da letra cursiva com crianças que ainda não estão alfabetizadas, o que será demonstrado no decorrer do texto.

Quanto à especificidade dos registros das professoras sobre o ensino e o uso das tipologias de letras nos artefatos pesquisados, notou-se que eles ocupam diferentes posições nos cadernos. Por vezes, estão situados na parte inferior ou superior da folha, em outras vezes, no lado direito ou esquerdo. Em algumas situações, eles respeitam a direção convencional de escrita e as linhas dos cadernos, em outras, estão inclinados sob as mesmas. O que se nota, de maneira preponderante, é que eles são redigidos nos "entre-espaços", nas "brechas", nos "espaços em branco" das folhas em que são copiadas e/ou fixadas as atividades propostas, ou seja, o mais próximo possível da escrita do aluno, como pode ser observado na figura a seguir:

\footnotetext{
${ }^{10}$ Implantado em 2005, no governo do presidente Luiz Inácio Lula da Silva - Partido dos Trabalhadores (2003 a 2011 ), o programa denominado Pró-Letramento - Mobilização pela Qualidade da Educação, foi elaborado em parceria com os sistemas de ensino e com as universidades propondo a Formação Continuada e Desenvolvimento da Educação em todo território Nacional (BRASIL, 2005). Foi considerado um programa de formação continuada oferecido aos professores que lecionavam nos cinco primeiros anos do Ensino Fundamental, tendo como proposta atuar nas áreas de alfabetização e a matemática.

${ }^{11}$ Sob o governo da presidenta Dilma Rousseff, no mês de julho de 2012, o Ministério da Educação (MEC) instituiu o Pacto Nacional pela Alfabetização na Idade Certa (PNAIC). De acordo a Portaria n ${ }^{\circ} 867$, de 4 de julho de 2012 , tem como principal finalidade alfabetizar as crianças até, no máximo, os oito anos de idade, ou seja, ao final do $3^{\circ}$ ano do ensino fundamental (BRASIL, 2012). A partir disso, foi investido na formação continuada de professoras e professores que atuavam no ciclo de alfabetização. Nos anos de 2013 e 2014 foram tratados, respectivamente, da alfabetização e da alfabetização matemática.
}

Rev. Iberoam. Patrim. Histórico-Educativo, Campinas (SP), v. 6, p. 1-23, e020015, 2020. 
FIGURA 1: Registros de professoras sobre as letras em cadernos de alunos do $1^{\circ}$ ano de escolarização. À esquerda caderno C12 $2007^{12}$ e, à direita, caderno C16 2015.
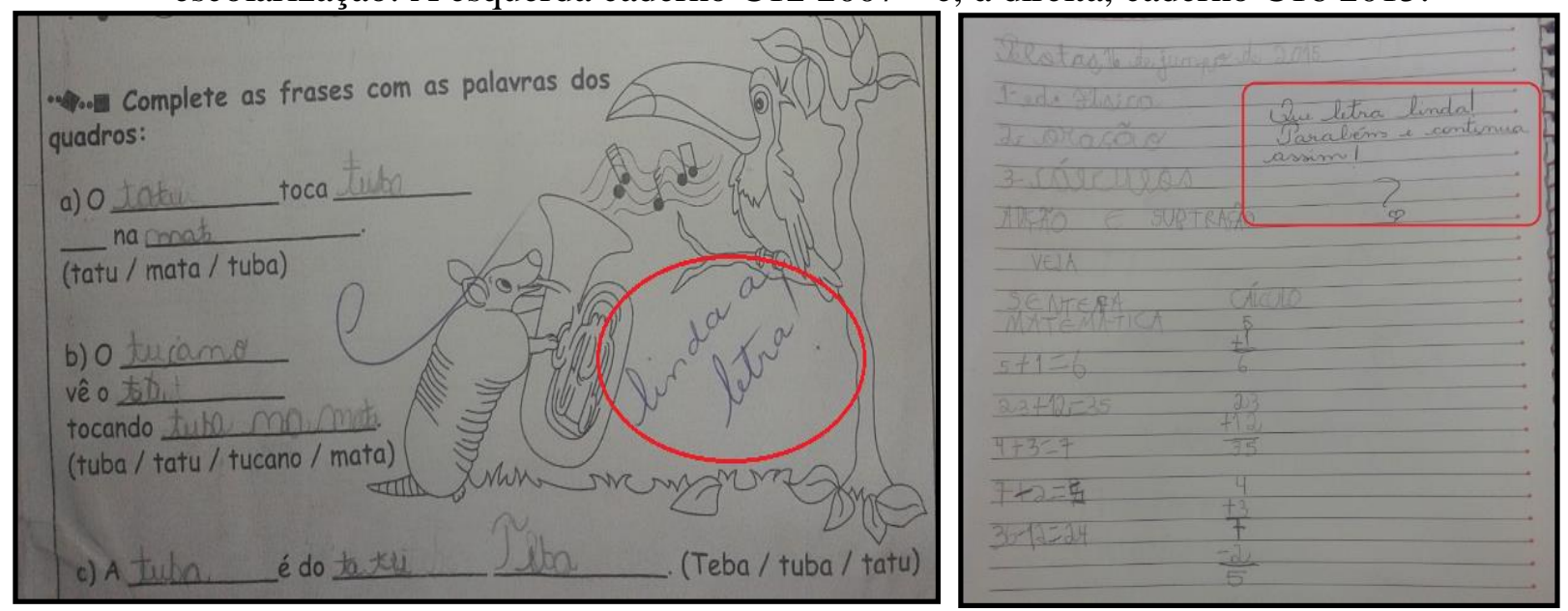

Fonte: Disponíveis no Acervo caderno de alunos do Centro de Memória Hisales.

Assim como nas frases apresentadas na Figura 1, a maioria dos registros das professoras foi feito à caneta, diferente das escritas das crianças que, geralmente, nesta etapa de ensino, são realizadas com o lápis grafite; o qual se tornou o principal instrumento de escrita da criança na escola (RAZZINI, 2008), principalmente pela possibilidade que o mesmo oferece de apagar e refazer a escrita, quantas vezes forem necessárias.

Do mesmo modo, indica-se a recorrência, por parte das professoras em seus registros, do uso da caneta de tinta azul. Além dessa, também foi identificado o uso de canetas com tintas de outras cores como preto, vermelho, rosa, de caneta hidrocor e também, do lápis grafite. Essa constatação é interessante na medida em que, de certa maneira, evidencia o rompimento de uma convenção histórica da escrita na escola, a saber: de que para realizar as correções no caderno deveria ser usada, quase que exclusivamente, a caneta vermelha, por permitir um contraste entre a escrita do docente e a do aluno (JACQUES, 2011). Sendo assim, nota-se, com o uso das canetas de tintas variadas, que ainda existe a intenção de contrastar a escrita da professora com as dos alunos, porém, rompendo com o uso de uma única cor de caneta.

Como também é perceptível a partir da Figura 1, os registros realizados pelas docentes estão, em sua maioria, redigidos com letra manuscrita. Mesmo que de maneira não tão usual, foram identificadas escritas com outros tipos de letras, como mostra a imagem a seguir:

\footnotetext{
${ }^{12}$ Código utilizado para catalogação no acervo.
} 
FIGURA 2 - Registro de uma professora em letra de imprensa minúscula (Caderno C52 2011).

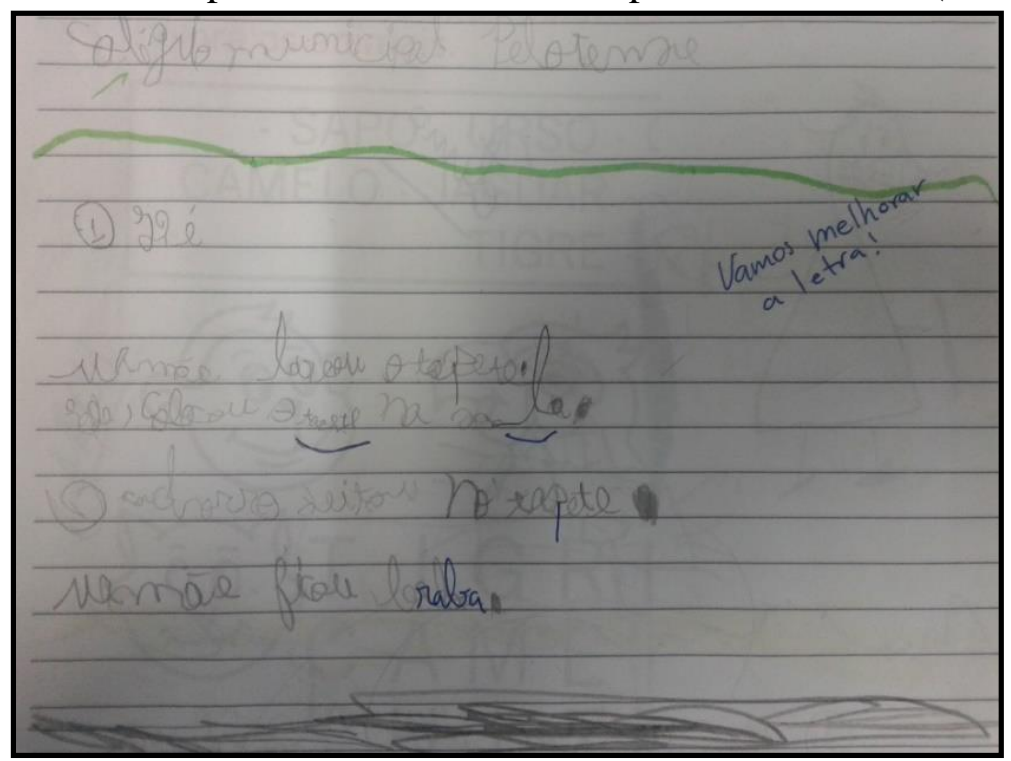

Fonte: Disponível no Acervo caderno de alunos do Centro de Memória Hisales.

Chama a atenção neste registro, que, mesmo o aluno escrevendo com a letra cursiva (por opção ou por cópia do quadro), a professora utiliza outra tipologia de letra (imprensa minúscula) para registrar a orientação de que ele deve melhorar a sua letra. Este exemplo é interessante à medida que demonstra que, em alguns momentos, as professoras rompem com a lógica de exclusividade do tipo de letra usado pelos alunos. Nesse sentido, alguns questionamentos são relevantes: o uso da letra imprensa minúscula pela professora, seria intencional para colocar a criança em contato com outros tipos de letras, como orienta, por exemplo, os Programas Próletramento (2008) e PNAIC (2012). Trata-se de uma opção pessoal da professora, em usar a letra de imprensa minúscula em suas escritas? É possível que a professora não tenha se preocupado com o tipo de letra a ser usado pelo fato de a sua escrita ser direcionada a outros leitores que não a criança, tais como pais/responsáveis e/ou direção escolar? São válidas a esse respeito, as ressalvas de Hébrard (2001) ao indicar que, muitas vezes, o registro diário nos cadernos é utilizado prova do trabalho escolar e, por isso, se destina a outros sujeitos, que não somente os alunos.

As Figuras 1 e 2, expostas anteriormente, também possibilitam constatar que os registros de professoras que estão sendo analisados neste artigo, tratam-se, na maioria, de escritas/frases curtas, geralmente, finalizadas com ponto de exclamação. Sobre este aspecto Jacques (2011, p.109) salienta que a "presença mais ou menos regular de frases que manifestam um predomínio 


\section{(c) $) \mathrm{EY}$}

emocional é reforçada pelo uso constante do ponto de exclamação ou, ainda, pelo uso do advérbio "que", conferindo maior intensidade a esses enunciados.". Ainda segundo a autora, "a presença regular e a homogeneidade no uso, talvez, se mantenham pelo mesmo princípio que fundamentam a organização gráfica do caderno escolar, pois, a cada ano letivo parece se manter, com discretas variações, o que talvez reforce seu caráter de tradição.” (JACQUES, 2011, p. 61). Entretanto, se os registros, muitas vezes, preservam padrões, mesmo em tempos e espaços variados, pode se dizer que eles também estão em constante devir, afinal, as professoras são protagonistas de suas ações, elas se apropriam ${ }^{13}$, (re)configuram, (re)criam e (re)inventam outras tantas formas de registros. É o caso, por exemplo, da escrita exposta abaixo:

FIGURA 3 - Registro da professora solicitando que melhore a letra em um caderno de $2^{\circ}$ ano de escolarização (Caderno C25 2015).

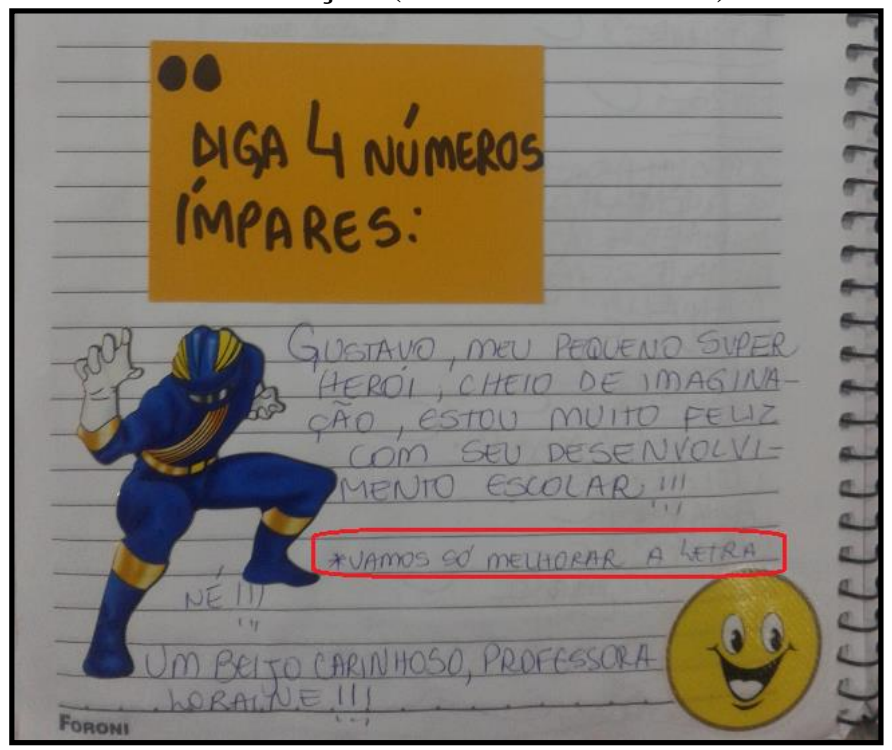

Fonte: Disponível no Acervo caderno de alunos do Centro de Memória Hisales.

Neste registro, localizado em um caderno do $2^{\circ}$ ano de escolarização, a professora faz uso de diferentes de figurinhas adesivas (emotion e super-herói), que vão sendo distribuídos na página, juntamente a sua escrita folha colorida. Nota-se que a professora procura envolver o aluno com algo que, provavelmente, seja de seu interesse como "os super-heróis". Entretanto, mesmo

\footnotetext{
${ }^{13} \mathrm{O}$ conceito de apropriação é entendido a perspectiva de Chartier (2003) e Certeau (2014) que consideram que os sujeitos interpretam e fazem usos diferenciados e opostos dos bens culturais. O "consumo" é uma produção astuciosa, dispersa e "quase invisível, pois não se faz notar com produtos próprios, mas nas maneiras de empregar os produtos impostos [...]” (CERTEAU, 2014, p. 39).
}

Rev. Iberoam. Patrim. Histórico-Educativo, Campinas (SP), v. 6, p. 1-23, e020015, 2020. 


\section{(cc) EY}

cativando o aluno, tecendo elogios sobre suas características e o seu desenvolvimento, de maneira sutil, ao final do "recado" ela apresenta a indicação de necessidade de o mesmo e melhorar a letra, uma vez que ele ainda não conseguiu atingir um traçado considerado ideal.

Como evidenciado por meio do exposto, as manifestações das professoras, por meio dos registros nos cadernos dos alunos, apresentam, em síntese, elogios, incentivos, solicitações e recomendações acerca do ensino e do uso dos diferentes tipos de letras. Tendo em vista esta diferenciação, passa-se a apresentar, primeiramente, as escritas das professoras cujos enunciados são referentes aos elogios e aos incentivos. Alguns exemplos são elucidados no quadro abaixo:

QUADRO 1 - Exemplos de escritas docentes com elogios e incentivos sobre as letras dos alunos entre os anos de 2000 e 2015.

\begin{tabular}{|c|c|}
\hline "Linda a Letra!" & "Linda letra!" \\
\hline "Que letra bonita!" & "Que letra Linda!" \\
\hline $\begin{array}{c}\text { "A profe adora a tua letrinha e a tua } \\
\text { organização! Continue assim tá!" }\end{array}$ & "Gostei da tua letra" \\
\hline $\begin{array}{c}\text { "Amei! Que letra linda!" "Parabéns } \\
\text { pela letra linda!" }\end{array}$ & "Que letra bonita! Continue \\
assim!"
\end{tabular}

Fonte: Quadro organizado pelas autoras a partir dos dados analisados.

Percebe-se nas frases e expressões exemplificadas no Quadro 1 o uso recorrente do adjetivo "linda"; que conforme o dicionário Aurélio significa algo "Excessivamente bonito; que chama a atenção pela beleza fora do comum; belo, belíssimo ou ainda, definido pela perfeição, pela harmonia e elegância; perfeita, harmoniosa, elegante"14. Ainda segundo o dicionário mencionado, à expressão "linda" corresponde a elogiar de forma intensa algo, principalmente, pelo seu caráter estético. Nesse sentido, percebe-se que o uso recorrente da palavra bonita, nas frases escritas pelas professoras, tem a intenção de demonstrar a 'satisfação' docente em relação à execução do traçado das letras realizado pelo aluno.

Contudo, no processo de aquisição e sistematização da escrita, além de traçar as letras, é preciso que a criança domine uma série de convenções construídas socialmente, as quais estipulam

${ }^{14}$ Capturado de: https://www.dicio.com.br/aurelio-2/

Rev. Iberoam. Patrim. Histórico-Educativo, Campinas (SP), v. 6, p. 1-23, e020015, 2020. 


\section{(cc) $\mathrm{EY}$}

regras e normas que precisam ser respeitadas, especialmente se tratando da escrita produzida no caderno escolar. É necessário assim, além de identificar as letras que são utilizadas para formar determinada palavra e realizar seu traçado, se apropriar das prescrições que envolvem a escrita e o uso do caderno escolar tais como: a escrita é realizada da direita para à esquerda, é preciso deixar um espaçamento entre as palavras para que elas consigam ser lidas, a letra deve ser traçada entre as linhas desenhadas no caderno e respeitar a margem, as palavras devem ser segmentadas ao final da linha e ter continuidade na linha seguinte, entre outras. Como destaca Viñao (2008, p. 22), “o caderno é um produto da cultura escolar, de uma forma determinada de organizar o trabalho em sala de aula, de ensinar e aprender, de introduzir os alunos no mundo dos saberes acadêmicos e dos ritmos, regras e pautas escolares".

Assim, da mesma maneira que os traçados das letras são elogiados pelas professoras, quando 'bem executados', todas essas aprendizagens e regras que envolvem a sistematização da escrita e o uso dos cadernos são também construídas e respeitadas pelos alunos, há o reconhecimento e o registro do mesmo pela professora. Nota-se isso no caderno C29 2011, quando a docente registra a frase "A profe adora a tua letrinha e a tua organização! Continue assim tá!".

Desse modo, é possível inferir que as frases “Linda a Letra!", "Parabéns pela linda letra!" e "Que letra linda! Parabéns e continue assim!", elucidam o quanto as professoras utilizam do registro escrito para demonstrar e incentivar a escrita dos alunos, e também, para reafirmar a necessidade de a escrita permanecer daquela determinada maneira. Ressalta-se, a partir destas frases, ser notória a preocupação das professoras com a boa letra. Conforme vem sendo apresentado, as professoras fazem questão de deixar registrado quando os alunos conseguem realizar um bom traçado, em relação ao que elas compreendem como a letra 'ideal'.

No entanto, a preocupação e a atenção com o bom traçado das letras e com a escrita legível das crianças faz parte da prática pedagógica docente há bastante tempo, sendo essa uma das principais questões presentes nas discussões dos modelos caligráficos (Vertical, Inclinado e Muscular), que ocorreu no começo e no decorrer do século XX (VIDAL; ESTEVES, 2003). Os modelos caligráficos abordavam diferentes discussões, todavia, os três tinham uma base comum, isto é, defendiam a boa letra, a letra rápida e elegante; a estética da letra era uma justificativa plausível à época. Entretanto, pelos registros das professoras entre os anos 2000 e 2015, percebese que a busca pelo traçado perfeito, tão almejado no período citado dos modelos caligráficos, de certa maneira, ainda persiste nos dias atuais. Conforme Magalhães (2007, p.10), a preocupação 


\section{$(\mathrm{cc})$ EY}

com o bom traçado ocorre ainda na atualidade porque a professora é um "oficial da escrita caligráfica (escolar)”, ou seja, “[...] sendo ele [ela] um prático da escrita caligráfica, cabe aferir a qualidade da escrita dos alunos com base na sua própria execução, com base na sua própria experiência.".

Apesar de atualmente essa discussão ter uma intensidade menor ${ }^{15}$, ainda constata-se, como referido, a intenção de que o aluno realize um traçado legível, perfeito. E quando isso ocorre, há a necessidade de externar, de registrar, por meio de escritas, o êxito do aluno. Para tanto, como mostram as análises, as professoras utilizam-se de elogios e incentivos. Todavia, quando a professora identifica que o traçado do aluno ainda não atingiu 'o esperado', e que, por isso, precisa ser aperfeiçoado, a docente também chama a atenção do aluno e demonstra sua preocupação, por meio de registros escritos.

Nesta perspectiva, identificamos no conjunto de cadernos analisados, as seguintes solicitações e recomendações:

QUADRO 2 - Exemplos de escritas docentes com solicitações e orientações sobre as letras dos alunos identificadas entre 2000 e 2015.

\begin{tabular}{|c|c|}
\hline "Melhorar a letra!" & "Aumentar a letra!" \\
\hline "Vamos melhorar a letra!" & "É preciso melhorar a letra" \\
\hline "Melhorar a letra ok!" & "Adorei Lucas! Mas olha essa \\
letra querido!"
\end{tabular}

Fonte: Quadro organizado pelas autoras a partir dos dados analisados.

Como elucidado no Quadro 2, verificou-se em diversos cadernos de alunos escritas docentes que expressam preocupação com a legibilidade da escrita das crianças e, principalmente

\footnotetext{
${ }^{15}$ Nos últimos, no Brasil, vem sendo intensificada a discussão de que cada sujeito possui peculiaridades e expressa sua personalidade também na caligrafia. Dessa maneira, são aceitáveis as diferentes possibilidades de traçado de uma mesma letra, ou seja, a sua multiplicidade, muito embora as professoras tentem impor traçados. Ou ainda, como expõe Magalhães (2005, p. 16), há um “[...] movimento de inovação pedagógica que se revela favorável a uma pessoalização da escrita, admitida e recomendada nos planos psicológico e didático, logo, desde as fases de aprendizagem". Sendo assim, aos poucos se rompe com a ideia de uma "letra modelar", exemplar, que deveria ser seguida por todos de forma padronizada, mas continua-se priorizando a legibilidade.
}

Rev. Iberoam. Patrim. Histórico-Educativo, Campinas (SP), v. 6, p. 1-23, e020015, 2020. 


\section{$(c)$ EY}

com o traçado das letras, a qual infere-se, pelas manifestações das professoras, não corresponder a um 'traçado ideal'.

Para exemplificar e aprofundar a discussão da legibilidade e do traçado das letras nos dados coletados para este artigo, a seguir são apresentadas três figuras que demonstram orientações, intervenções e indicações de atividades para que os alunos aperfeiçoassem suas escritas.

No primeiro exemplo, na Figura 4, observa-se que após registrar a pregunta "Vamos melhorar a letra?", a professora lista todas as letras do alfabeto no tipo cursivo para que a criança reproduza os seus traçados até o final da linha.

FIGURA 4 - Registro da professora para melhorar a letra. Caderno $2^{\circ}$ ano de escolarização (Caderno C20 2011).

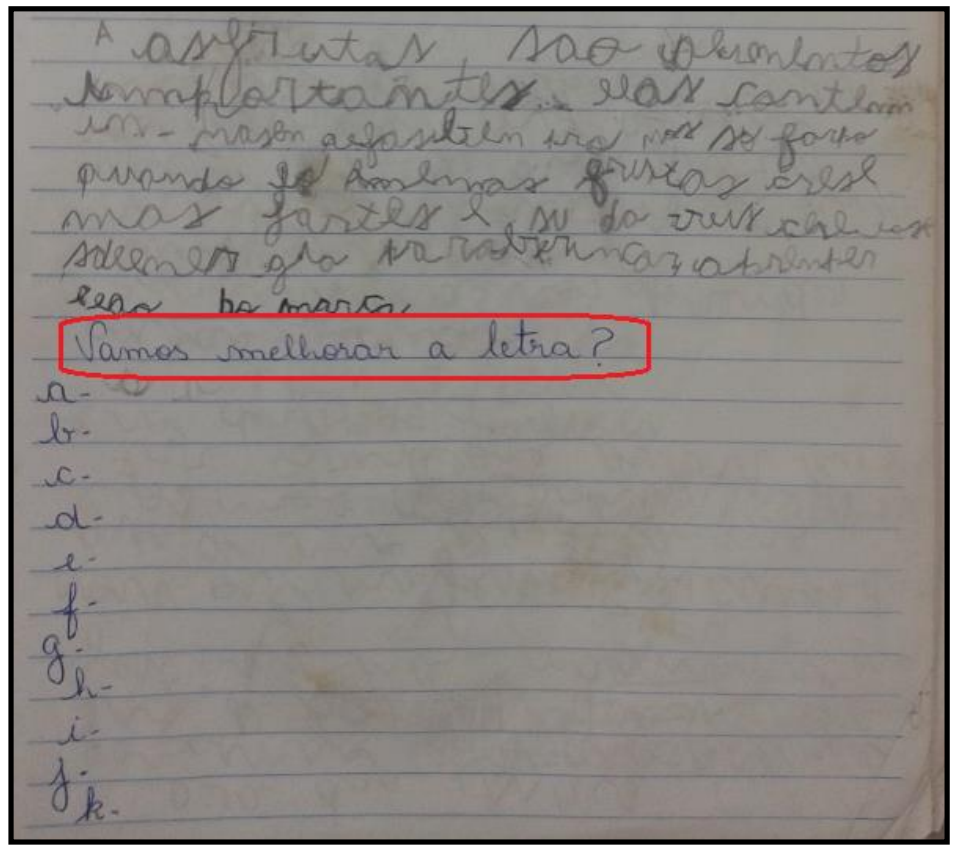

Fonte: Disponível no Acervo caderno de alunos do Centro de Memória Hisales.

Neste sentido, infere-se que, na compreensão da professora, para aprender a traçar as letras com perfeição é necessário muito esforço, treino e cópia; concepção pedagógica esta que era bastante recorrente na primeira metade do século XX, principalmente, pelas discussões vinculadas aos modelos caligráficos. A cópia, o encher linhas são estratégias usuais, principalmente, quando se trata do ensino da letra do tipo cursiva. Conforme Soares (2001), ao investir nesse tipo de atividade a professora acredita que para aprender a escrever, a traçar as letras, a criança precisa treinar, imitar, repetir e praticar. Logo, essa maneira de compreender o ensino da escrita, nas classes 


\section{$(\mathrm{cc}) \mathbf{E Y}$}

iniciais de escolarização, entende o aluno como um sujeito passivo, que aprende devido a sua dedicação e ao seu esforço.

Na Figura 5, apresentada a seguir, a atividade indicada pela professora é cobrir os pontilhados organizados na folhinha fotocopiada. No entanto, essa estratégia parece não ter atingido a expectativa docente, uma vez que nota-se no canto superior direito da figura, em caneta vermelha, o registro da seguinte frase: "Mesmo com a linha pontilhada ficou difícil de realizar a tarefa".

FIGURA 5 - Atividades indicadas pelas professoras para treinar o traçado da letra. A esquerda Cadernos C1 2012 e a direita C14 2013.
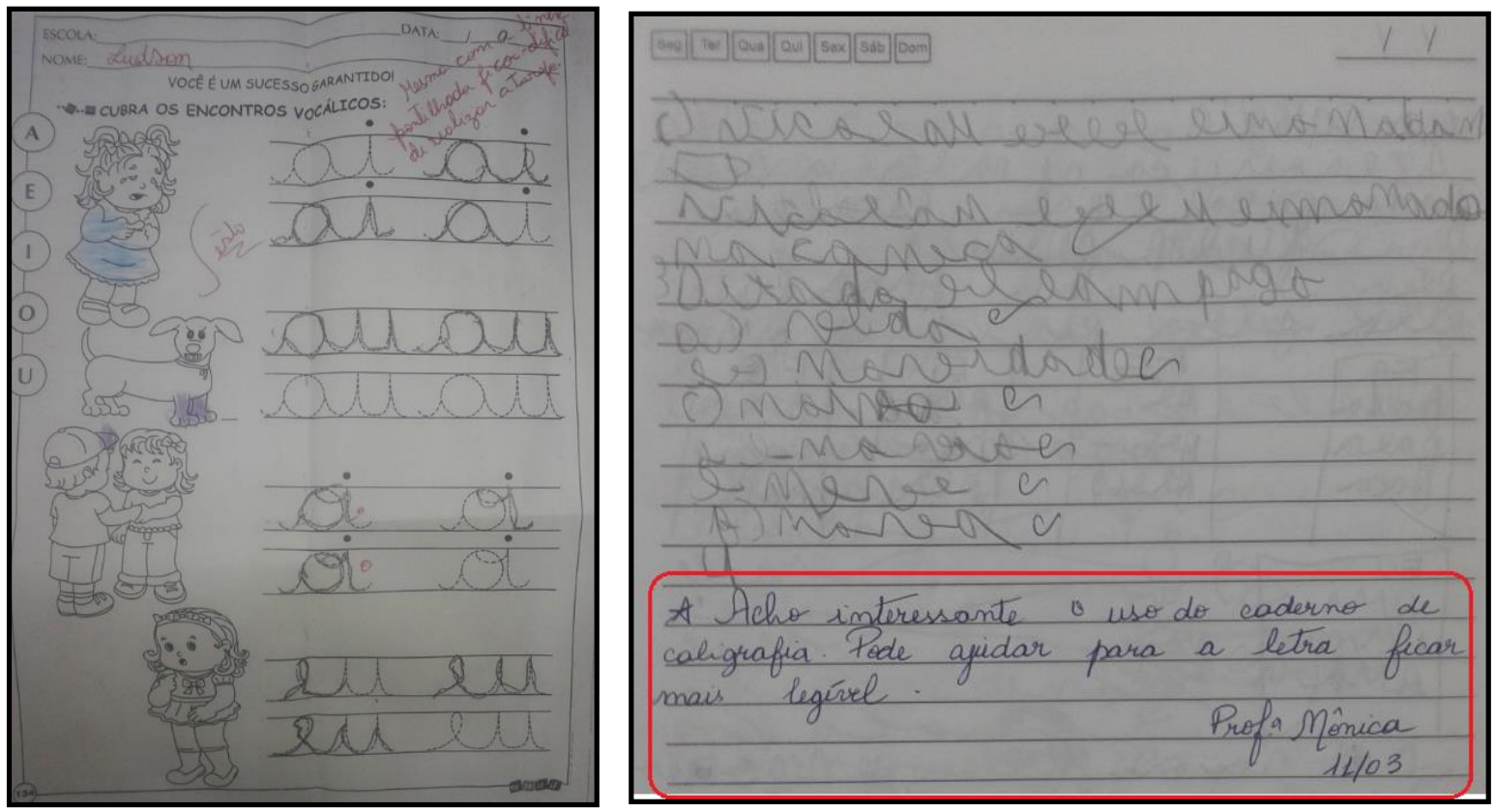

Fonte: Disponíveis no Acervo caderno de alunos do Centro de Memória Hisales.

Além dos aspectos ressaltados, a Figura 5 mostra o registro da professora sugerindo, possivelmente para os responsáveis da criança, o uso do caderno de caligrafia e enfatizando que o mesmo pode ser um recurso para auxiliar o aluno a ter uma letra mais legível. O caderno de caligrafia, normalmente é composto de letras, palavras e frases em letra no tipo cursiva para serem reproduzidas seguindo o modelo estabelecido. Um recurso pedagógico e cultural utilizado com a intenção de melhorar o traçado das letras, principalmente, a cursiva. Para Grazziotine e Gastaud (2010, p. 222), o caderno de caligrafia "faz da intencionalidade de repetição mecânica com fins técnicos, um lugar de doutrinação em função de outros objetivos que vão além do caráter meramente "anatômico" da escrita." Sendo assim, considera-se que para alcançar uma boa letra é 


\section{(cc) EY}

necessário aprender técnicas de aperfeiçoamento, muitas vezes, baseadas em exaustivas cópias. Nesse sentido, pode-se afirmar que:

Uma boa letra implica praticar disciplinadamente, através de muito treino de mão e domínio de um tipo instrumental específico, uma sucessão de gestos que faz o professor e que imitam os alunos, que aprendem pelo esforço, pela repetição, pela regularidade e pelo equilíbrio. (STEPHANOU; BASTOS, 2012, p. 112).

De forma geral, as Figuras 4 e 5, apresentadas anteriormente, demonstram que além de manifestar, por meio do registro escrito, a necessidade de qualificar e melhorar o traçado das letras e a legibilidade da escrita, as professoras utilizam de diferentes atividades e recursos para que os alunos atinjam este fim. Nota-se que aprender a escrever com clareza e destreza é uma das intencionalidades pedagógicas que os docentes vêm dando ênfase no trabalho desenvolvido nos primeiros anos da escolarização.

Logo, é possível concluir que mesmo com a disseminação da ideia de flexibilização da escrita (MAGALHÃES, 2005) nos debates do campo da alfabetização, quando se trata da escrita escolar e, mais especificamente, do ensino da letra do tipo cursiva, ainda se atribui muita importância ao traçado perfeito e a legibilidade da escrita. Corrobora essa assertiva o fato de se ter evidenciado que as sugestões e indicações de atividades de treino e cópia são atreladas, com mais recorrência ao uso da letra cursiva do que as demais tipologias.

Em suma, pode-se dizer que o conjunto de 200 cadernos de alunos que foram analisados para este artigo, evidenciam, no mínimo, dois aspectos relevantes. O primeiro, é que é perceptível uma maior aceitação da escrita das crianças da maneira como ela é feita, pois mesmo não conseguindo executar um belo traçado há, em alguns casos, o incentivo e o reconhecimento por parte do docente. Um exemplo, nesta direção, pode ser observado na imagem a seguir, em que a professora, mesmo não registrando em sua escrita a necessidade de o aluno melhorar a sua letra, ela faz a correção/intervenção sobre a própria escrita da criança 
FIGURA 6 - Aceitação e flexibilização da escrita escolar (Caderno C1 2008).

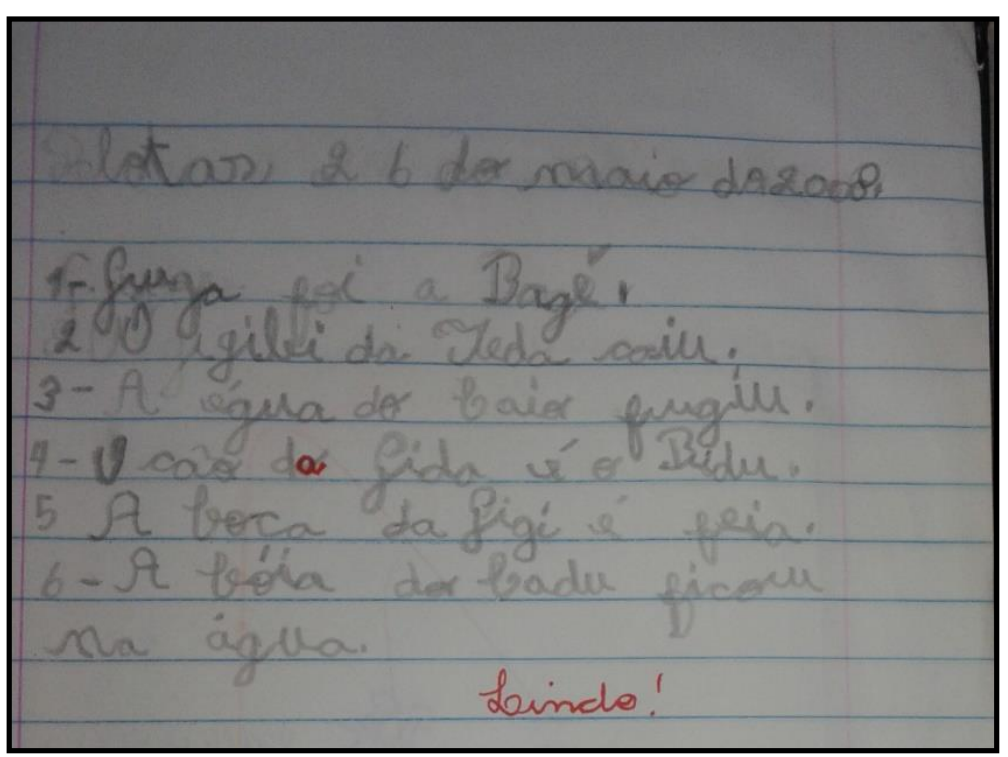

Fonte: Disponíveis no Acervo caderno de alunos do Centro de Memória Hisales.

O segundo aspecto relevante a considerar, é que se observou ser reincidente, ainda nos dias atuais, certa preocupação com o traçado perfeito das letras, especialmente no que diz respeito ao ensino e ao uso da letra do tipo cursiva. Para tanto, os registros demonstram que as professoras utilizam-se de um conjunto de estratégias baseadas, basicamente, na repetição e no treino do traçado de letras.

\section{CONSIDERAÇÕES FINAIS}

Neste texto, tivemos como objetivo analisar registros de professoras em cadernos de alunos que apresentavam indicações, sugestões e orientações quanto ao ensino e aos usos dos diferentes tipos de letras. A análise realizada no conjunto de 200 cadernos, que estão sob a salvaguarda de um Centro de Memória brasileiro (Hisales), possibilitou perceber o registro de observações referentes aos traçados das letras das crianças é reincidente até os dias atuais nas práticas pedagógicas que envolvem o processo de aquisição e sistematização da escrita.

Mesmo, por vezes, assumindo características singulares, foi possível observar que os registros das professoras seguem um determinado padrão, a saber: frases curtas, redação em letra cursiva, com caneta de tinta azul e o mais próxima possível da escrita das crianças. Da mesma maneira, identificou-se que em síntese, eles expressam a preocupação das professoras em relação ao traçado das letras e a legibilidade da escrita. Assim, por um lado, quando constatado que a letra 


\section{$(c c)$ EY}

estava legível, caprichada, bem traçada, eram redigidos elogios e incentivos para que os alunos continuassem se empenhando e escrevendo daquela maneira. Por outro lado, quando a professora considerava que a letra ainda não era estava legível, ou com um traçado ideal, eram escritas orientações que chamavam a atenção da criança para a melhoria da caligrafia. Além disso, geralmente nestes casos, eram indicadas sugestões de atividades de treino para o aperfeiçoamento do traçado das letras como, por exemplo, encher a linha, cobrir os pontos que formam a letra, entre outras.

É importante destacar que estes últimos registros e indicações de atividades estavam vinculados, especialmente, ao uso da escrita da letra do tipo cursiva. Observou-se, desse modo, que mesmo existindo nos dias atuais, em virtude de discussões no campo da alfabetização e orientações nos documentos oficiais brasileiros, uma maior flexibilização da escrita, quando se trata do uso da letra cursiva ainda há uma exigência maior em relação ao traçado perfeito da letra; o que implica na ressalva de que há a compreensão de que para esse tipo de letra é necessário mais técnicas e treinos. Considerando estes aspectos observados, vale salientar que o cuidado com o traçado das letras no processo de alfabetização é um debate que passa por diferentes períodos históricos, o qual esteve vinculado à discussão dos modelos caligráficos (século XX) que tinham como uma das suas principais características a busca pela boa letra.

Tendo em vista as reflexões e análises apresentadas neste artigo, vale ressaltar a relevância das pesquisas em cadernos escolares. Mesmo que esses suportes apresentem "limitações enquanto objeto/fonte de investigação, uma vez que, obviamente, eles não dizem tudo do cotidiano da sala de aula, das professoras e dos alunos. Nem tudo o que se passa na sala de aula é registrado" (PERES, 2012, p. 96), eles possibilitam indícios de práticas desenvolvidas em um determinado tempo e espaço. Desse modo, os testemunhos escritos de professoras, materializados, neste caso, nos cadernos de alunos em fase inicial do processo de escolarização contribuem para compreender não só aspectos da cultura escolar e da cultura material, mas também problematizar concepções, estratégias e recursos que respaldam, muitas vezes, as práticas pedagógicas desenvolvidas no contexto escolar no processo de aquisição e sistematização da escrita, especialmente no que tange ao ensino e o uso dos diferentes tipos de letras. 


\section{REFERÊNCIAS}

ANDRÉS, Maria del Mar del Poso; ZAMORA, Sara Ramos. Representação da escola e da cultura escolar nos cadernos infantis (Espanha, 1922-1942). In: MIGNOT, Ana Chrystina (Org.). Cadernos à vista: escola, memória e cultura escrita. Rio de Janeiro: Ed. EdUERJ, 2008.

BRASIL/MEC. Pró-Letramento: Programa de Formação Continuada de Professores dos Anos/Séries Iniciais do Ensino Fundamental: alfabetização e linguagem. - Ed. rev. e ampl. incluindo SAEB/Prova Brasil matriz de referência/ Secretaria de Educação Básica - Brasília: Ministério da Educação, Secretaria de Educação Básica, 2008.

BRASIL/MEC. Lei no . 11.274, de 6 e fevereiro de 2006. Altera a redação dos artigos 29, 30,32 e 87 da Lei no .9 .394 , de 20 de dezembro de 1996, que estabelece as diretrizes e bases da educação nacional, dispondo sobre a duração de 9 (nove) anos para o ensino fundamental, com matrícula obrigatória a partir dos 6 anos de idade. Diário Oficial da República Federativa do Brasil, Brasília, DF, 2006.

BRASIL/MEC. Manual do pacto: Pacto pela Alfabetização na Idade Certa: o Brasil do futuro com o começo que ele merece. Brasília, DF, 2012.

CAGLIARI, Luiz Carlos. Alfabetização sem o Bá-Bé-Bi-Bo-Bu. São Paulo: Scipione, 2009.

CERTEAU, Michel de. A invenção do cotidiano. 22. ed. Rio de Janeiro: Vozes, 2014.

CHARTIER, Roger. Formas e sentido. Cultura escrita: entre distinção e apropriação. Trad. Maria de Lourdes Meirelles Matendo. Campinas, SP: Mercado de Letras, 2003. (Coleção História da Leitura)

CHARTIER, Anne-Marie. Um dispositivo sem autor: cadernos e fichários na escola primária. Revista Brasileira de História da Educação. Campinas, n. 3, p. 9-26, jan./jun. 2002.

CHARTIER, Anne-Marie. Exercícios escritos e cadernos de alunos: reflexões sobre práticas de longa duração. In: CHARTIER, Anne Marie. Práticas de leitura e escrita: história e atualidade. Belo Horizonte: Autêntica. CEALE, 2007. (Coleção Linguagem e educação)

CORDOVA, Tania. A escola normal em Lages (SC): lentes no presente e deslocamentos ao passado (2015-1933). 2017. 386 f. Tese (Doutorado em Educação) - Centro de Ciências Humanas e da Educação, Universidade do Estado de Santa Catarina, UDESC, Florianópolis, 2017.

GÓMEZ, Antonio Castillo. Educação e cultura escrita: a propósito dos cadernos e escritos escolares. Revista Educação, Porto Alegre, v. 35, n. 1, p. 66-72, jan./abr. 2012.

GÓMEZ, Antonio Castillo. Los Cuadernos escolares a la luz de la História de la cultura escrita. 2010. Disponível em: 


\section{$(\mathrm{cc})$ EY}

https://ebuah.uah.es/dspace/bitstream/handle/10017/6758/Cuadernos\%20Escolares.pdf?sequence =1\&isAllowed=y. Acesso em: 12 mar. 2018.

GRAZZIOTINE, Luciana; GASTAUD, Carla. Nos traços de caligrafia, indícios de um tempo escolar. Revista História da Educação, v. 14, n. 30, p. 207-226, enero-abril, 2010.

GVIRTZ, Silvina. El discurso escolar a través de los cuadernos de clase: Argentina 1930 1970. Buenos Aires: Eudeba, 1996.

GVIRTZ, Silvina; LARRONDO, Marina. Os cadernos de classe como fonte primária de pesquisa: alcances e limites teóricos e metodológicos para sua abordagem. In: MIGNOT, Ana Chrystina Venâncio (Org.). Cadernos à vista: escola, memória e cultura escrita. Rio de Janeiro: EdUERJ, 2008.

HÉBRARD, Jean. Por uma bibliografia material das escritas ordinárias: a escritura pessoal e seus suportes. In: Mignot, A. C.V; Bastos, M. H. C., Cunha, M. T. S. (Org.). Refúgios do eu: educação, história, escritas autobiográficas. Florianópolis: Mulheres, 2000.

HÉBRARD, Jean. Por uma bibliografia material das escritas ordinárias: o espaço gráfico do caderno escolar (França - séculos XIX-XX). Revista Brasileira de História da Educação. Campinas, n. 1, p. 115-141, jan./jun. 2001.

HÉBRARD, Jean. A lição e o exercício: algumas reflexões sobre a história das práticas escolares de leitura e escrita. Revista Educação Santa Maria, v. 32, n. 1, 2007.

FISCHER, Rosa. Maria. Foucault e a análise do discurso em educação. Cadernos de Pesquisa, São Paulo, n. 114, p. 197-223, nov. 2001.

FONTOURA, Afro de Amaral. A escola viva: metodologia do ensino primário. 9. ed. Rio de Janeiro: Aurora, 1963.

JACQUES, Alice Rigoni. As marcas de correção em cadernos escolares do curso primário do Colégio Farroupilha/RS 1948/1958. Dissertação (Mestrado em Educação) - Pontifícia Universidade Católica do Rio Grande do Sul, Porto Alegre/RS, 2011.

LOPES, Isa Cristina da Rocha. Memória e discurso em marcas de correção: um estudo de cadernos escolares. Dissertação (Mestrado em Memória Social) - Universidade Federal do Estado do Rio de Janeiro, Rio de Janeiro/RJ, 2006.

LOPES, Isa Cristina da Rocha. Cadernos escolares: memória e discurso em marcas de correção. In: MIGNOT, Ana Chrystina Venâncio (Org.). Cadernos à vista: escola, memória e cultura escrita. Rio de Janeiro: EdUERJ, 2008.

MAGALHÃES, Justino. Escrita escolar e oficialização da escola Portuguesa. In: VIII Congreso Internacional História de la Cultura Escrita. Universidad de Alcalá, 5 a 8 de julio de 2005. Sección $3^{\text {a }}$ : Escrituras cotidianas em contextos educativos. 2005. 
MIGNOT, Ana Chrystina. Um certo objeto-memória: apontamentos sobre cadernos escolares. In: III Seminário Internacional Redes de conhecimento e a tecnologia: imagem e cidadania, 2005, Rio de Janeiro. Anais do III Seminário Internacional Redes de conhecimento e a tecnologia: imagem e cidadania, 2005.

MIGNOT, Ana Chrystina. Um objeto quase invisível. In: MIGNOT, Ana Chrystina Mignot (Org.). Cadernos à vista: escola, memória e cultura escrita. Rio de Janeiro: Ed. EdUERJ, 2008a.

MIGNOT, Ana Chrystina. Não me esqueça num canto qualquer. Rio de Janeiro: Educação e Imagem, 2008b. CD-ROM.

MONKS, Joseane Cruz. Do artesanal ao digital: uma genealogia dos meios de produção e reprodução de folhinhas de atividades em cadernos de alunos. 2019. $152 \mathrm{f}$. Dissertação (Mestrado em Educação) - Faculdade de Educação/FaE, Universidade Federal de Pelotas/UFPel, Pelotas, 2019.

MORAES, Artur Gomes. Sistema de escrita alfabética. São Paulo: Melhoramentos, 2012.

NEUBERT, Caroline Guião Coelho. Os Sentidos Atribuídos pelas Crianças aos seus Cadernos Escolares. Dissertação (Mestrado em Educação) - Universidade Federal de Santa Catarina, Florianópolis/SC, 2013.

PERES, Eliane; BARUM, Sylvia Tavares. O ditado escolar sob o enfoque histórico: um estudo a partir de cadernos de crianças em processo de alfbetização. In: IX Congresso Iberoamericano de História da Educação Latino-Americana, 2009, Rio de Janeiro. Anais do IX Congresso Iberoamericano de História da Educação Latino-Americana, 2009. v. 1. p. 1-8.

PERES, Eliane. A alfabetização vista através de cadernos escolares (1958-2009). In: XV ENDIPE - Encontro Nacional de Didática e Prática de Ensino, 2010, Belo Horizonte. Anais do XV ENDIPE - Encontro Nacional de Didática e Prática de Ensino. Belo Horizonte: UFMG, 2010 .

PERES, Eliane. Um estudo da história da alfabetização através dos cadernos escolares (19432010). Cadernos de História da Educação. v.11, n. 1 - jan./jun. 2012.

RAZZINI, Marcia de Paula G. Instrumentos de escrita na escola elementar: tecnologias e práticas. In: MIGNOT, Ana Chrystina (Org.). Cadernos à vista: escola, memória e cultura escrita. Rio de Janeiro: Ed. EdUERJ, 2008.

VIÑAO, Antonio. Os cadernos escolares como fonte histórica: aspectos metodológicos e historiográficos. In: MIGNOT, Ana Chrystina (Org.). Cadernos à vista: escola, memória e cultura escrita. Rio de Janeiro: Ed. EdUERJ, 2008.

VIDAL, Diana. G.; ESTEVES, I.L. Modelos caligráficos concorrentes: as prescrições para a escrita na escola primária paulista (1910-1940). In: PERES, E., TAMBARA, E. (Org.). Livros 


\section{(cc) EY}

escolares e ensino da leitura e da escrita no Brasil (séculos XIX - XX). Pelotas/RS: Seiva, 2003.

SANTOS, Vera Mendes dos. Caderno escolar: um dispositivo feito peça por peça para a produção de saberes e subjetividade. Anais: IV Reunião Científica Regional da ANPEd (ANPEd-Sul), Santa Catarina/SC, 2002.

SOARES, Magda. Aprender a escrever, ensinar a escrever. In: ZACCUR, E. (org.). A Magia da Linguagem. Rio de Janeiro: DP\&A: SEPE, 2001.

STEPHANOU, Maria; BASTOS, Maria Helena Câmara. Da sensibilidade das mãos à harmonia da escrita: Memórias, artefatos e gestos da caligrafia na história da educação. In: TRINCHÃO, Gláucia Maria da Costa (Org.). Do desenho das belas letras à livre expressão do desenho da escrita. Salvador: EDUFBA, 2012.

Recebido em: 31 de agosto de 2020 Aceito em: 11 de setembro de 2020 